\title{
What preconceptions and attitudes about engineering are prevalent amongst upper secondary school pupils? An international study
}

\author{
Ümit Köycü $^{1}$ - Marc J. de Vries ${ }^{1}$
}

Accepted: 10 March 2015/Published online: 24 March 2015

(C) The Author(s) 2015. This article is published with open access at Springerlink.com

\begin{abstract}
In the Netherlands, as well as in many other countries, there is an increasing interest in implementing education about engineering as a part of general education at the upper secondary school level. In order to know what pupils at that level think about engineering, a study has been done to investigate their attitude towards and their concept of engineering. This study was done not only in the Netherlands but also in 39 other countries. In the preparation of the study, pupils were asked to draw concept maps of what they thought engineering was about. In the quantitative main part of the study, pupils were asked to respond to 33 Likert-type attitude items and 32 concept-items of the same type. A factor analysis was done in order to reveal the dimensions in the pupils' attitude and concept. In contrast to studies carried out amongst students in lower secondary school levels, a fairly clear concept about engineering was found. The gender differences relating to engineering, found in lower secondary education, were not found in upper secondary education. The prevalent attitude of students towards engineering indicated a fairly positive image of engineering.
\end{abstract}

Keywords Attitudes · Concepts · Engineering · Upper secondary school

\section{Introduction}

In order to create suitable lesson materials on engineering for upper secondary school, the first step is to get an accurate measurement of the pre-existing concept and image pupils have when being introduced to engineering as a new subject.

The aim of this article is to investigate the pre-existing image pupils have regarding engineering before this subject is implemented in the upper high school study curriculum.

Ümit Kőycű

umitkoycu@gmail.com

1 Delft University of Technology, Delft, The Netherlands 
In many countries, engineering emerges as a new element in technology education. In the USA this has even caused a name change for the technology teachers' association: it was renamed from International Technology Education Association (ITEA) into International Technology and Engineering Engineering Association (ITEEA). Moreover the National Academy of Engineering (NAE) emphasizes the significance of engineering education at pre-university level (Committee on Standards for K-12 Engineering Education 2010). It is also visible in the acronym STEM (Science, Technology, Engineering and Mathematics), which increases rapidly in popularity in the USA and in the UK. In the Netherlands, there is not yet a substantial movement towards introducing engineering in secondary schools, but first initiatives are present at the moment. In the 1980s, when several countries introduced technology education as a successor to some kind of craft education, studies into pupils' attitudes and concepts towards technology appeared to be informative with respect to the ideas that pupils have in mind when they enter technology education. Many of these studies were done in the context of the Pupils' Attitudes Towards Technology (PATT) movement. A PATT questionnaire was developed (Bame et al. 1993) and used in many countries (de Klerk Wolters et al. 1990) and PATT conferences were held in order to bring together researchers and other people involved in technology education, to provide a discussion platform for PATT-related issues. With this in mind, we decided to do a similar study on engineering. PATT studies began in lower secondary education, as this was the level of education at which technology education was compulsory in most countries. For engineering, upper secondary level seems to be a good starting point, as it often requires more knowledge of scientific concepts and principles and mathematics that pupils build up in lower secondary education. So we decided conduct a study into upper secondary pupils' attitudes towards and concepts of engineering, similar to the PATT studies for technology. As part of the success of PATT is its international character, we also decided to make our research study an international one. One of us, Umit Koycu, is a secondary school teacher with a wide network of international contacts, which had been build up in the course of many years of involvement in international science and technology education competitions for schools.

So far, little has been done in this domain. This has been noted in the CCETE study (Hacker et al. 2009), which is aimed toward formulating core concepts for engineering education. The concepts "design (as a verb)", "system", "modeling”, "social interaction", and "optimization" were given the highest average score by the Delphi experts. There are very few studies on what pupils think about engineering. One study reported on the development of a drawing test for students in grades 3-5, 6-8 and 9-12 in the USA (Knight and Cunningham 2004). They found that engineering was mostly associated with designing. Karatas, Mickos and Bodner did a study among grade six students in the USA and found that for that age level the students' images of engineering were 'fragile, or unstable' (Karatas et al. 2010). Evidently, not much is known yet about what senior secondary school children think about engineering. This research aims to elucidate the preconceptions prevalent amongst students in grades 9-12. A subsequent study will be aimed at identifying the influence of lesson materials on the results of engineering education.

\section{Research methodology}

In the preparatory part of this study, we used concept maps to explore the pupils' concept of engineering. 
As our study was meant to be similar to PATT studies, we decided to use similar instruments. For technology, the dimensions in the pupils' attitudes were well known from the many PATT studies, in which these dimensions were found quite consistently in various countries. There is always an 'interest' dimension, one that reflects 'importance' of technology, 'accessibility' of technology, a gender dimension, a career dimension and a dimension that reflects assessment of technology (is it good or bad?). We started by assuming that similar dimensions would be present for engineering. Therefore we developed a questionnaire, similar to the PATT questionnaire, consisting of Likert-type items related to the dimensions as mentioned. We decided, however, first to do an exploratory qualitative study into pupils' image of engineering, using concept maps. These had not been used in PATT studies before. In those studies, pupils were often asked to write short essays. As we aimed at doing an international study, we realized that getting essays from a wide range of countries, in many of which English is not the mother tongue of the pupils, so we decided to use a method that contains less words and yet allows pupils in an equal way to express their ideas. Additionally, concerns regarding the use of this instrument in some countries based on their formulation and language were assuaged by using translations in the primary language of these countries (Spanish, Chinese, Arabic, Russian, Turkish, German, Japanese, Dutch and French). Since the 1980s when the PATT studies began, concept maps have become an increasingly popular research method with as an additional advantage that many teachers also use it in their teaching to help pupils develop understanding of concepts and their relations. As in PATT studies, we also developed Likert-type concept items in the questionnaire. We used the concept maps to develop those items. The items were formulated as topics of which pupils had to identify to which extent they were associated with engineering. We had to think carefully about the distinctions between technology and engineering in order not to do another PATT study. We chose to focus on two differences:

1. engineering is limited to certain professions while technology is something all people can be involved in, and

2. engineering is only about developing new technologies (designing, producing), while technology is also about using products.

As we were interested in investigating differences between subpopulations, we added some background variables, similar to the way that was done in PATT studies: pupils' age, gender, class, father's and mother's professions, experience with technology (toys, computers, museums), engineers among relatives and the presence of a school subject on engineering in their curriculum. The questionnaire, which was administered between September 2010 and February 2012, consists of 65 items. 33 of these items dealt with attitude while the remaining 32 were aimed at understanding their concept of engineering. Pupils filled the questionnaire in approximately $15 \mathrm{~min}$. Some examples of items are;

1. I always want to install or try something that I have bought

2. Both men and women can be a good engineer

3. To become an engineer you have to follow difficult courses

4. An engineer is useful for its country

5. Perhaps I want to become an engineer in the future

The questionnaire was developed in such a way that it could be filled in electronically. This facilitated distribution worldwide and enabled faster processing as the data were available in an electronic form (as an Excel file) immediately. With the intervention of colleague-teachers in participating countries, the questionnaire was administered among 
7591 upper secondary pupils. Both urban and rural schools were included, in a representative balance for each country. Pupils in 13 countries drew concept-maps, which were aggregated to a total of 31 concept maps, with each country corresponding to two or three concept maps. The item scores and scores on background variables were processed through the SPSS program.

In Table 1 the number of respondents (pupils) from the clusters of countries is presented.

Per country one or two schools were involved. In some cases the schools were in very different parts of the country. This means that the overall scores that we present here are a result of mixing pupils from very different contexts. The numbers are, of course, small for a worldwide study, and the sample is by no means representative for a country. The number of pupils per country is too small to draw any reliable conclusions about that individual country. Besides that, it was not our purpose to draw conclusions for individual countries. Our reason for administering the questionnaire worldwide is to get a first impression of possible differences between different regions and cultures. In order to reach that goal, we have clustered the countries, depending on certain similarities (level of technological development, economy, culture, etcetera). The following clusters we have made: Western Countries, Latin America, Africa, Far-East, South Asia, Middle East, Former Soviets and Eastern Europe.

In this article the main focus is on the quantitative analysis of data (the questionnaire). The qualitative part fo the study (the concept maps) was used as a basis for the quantitative instrument (the questionnaire).

\section{Results: qualitative part (concept maps)}

We will now present the outcomes of the preparatory part of the study, by using concept maps to explore the pupils' concept of engineering. We have presented some examples of the concept maps in Fig. 1. Many of the concept maps revealed a level of sophistication that was surprisingly high compared to the outcomes of many PATT studies in which the

Table 1 Number of respondents from clusters of countries

\begin{tabular}{|c|c|c|c|c|}
\hline Cluster & Countries & Male & Female & Total \\
\hline Africa & Kenya, South Africa, Nigeria & 341 & 347 & 688 \\
\hline Eastern Europe & Bulgaria, Poland, Hungary, Romania, Turkey & 443 & 430 & 873 \\
\hline Far East & P. R. China, South-Korea, Japan & 372 & 375 & 747 \\
\hline Former Soviets & $\begin{array}{l}\text { Turkmenistan, Georgia, Azerbaijan, } \\
\text { Kazakhstan, Russia }\end{array}$ & 486 & 509 & 995 \\
\hline Latin America & Mexico, Argentina, Chile, Colombia, Brazil & 199 & 197 & 396 \\
\hline Middle East & Iran, Iraq, Morocco, Yemen, Egypt & 235 & 217 & 452 \\
\hline South Asia & Bangladesh, Pakistan, Indonesia, India & 554 & 512 & 1066 \\
\hline \multirow[t]{2}{*}{ Western Countries } & $\begin{array}{l}\text { Canada, USA, England, Netherlands, Belgium, } \\
\text { France, Germany, Israel, Australia, New Zealand }\end{array}$ & 1185 & 1189 & 2374 \\
\hline & Total & 3815 & 3776 & 7591 \\
\hline
\end{tabular}



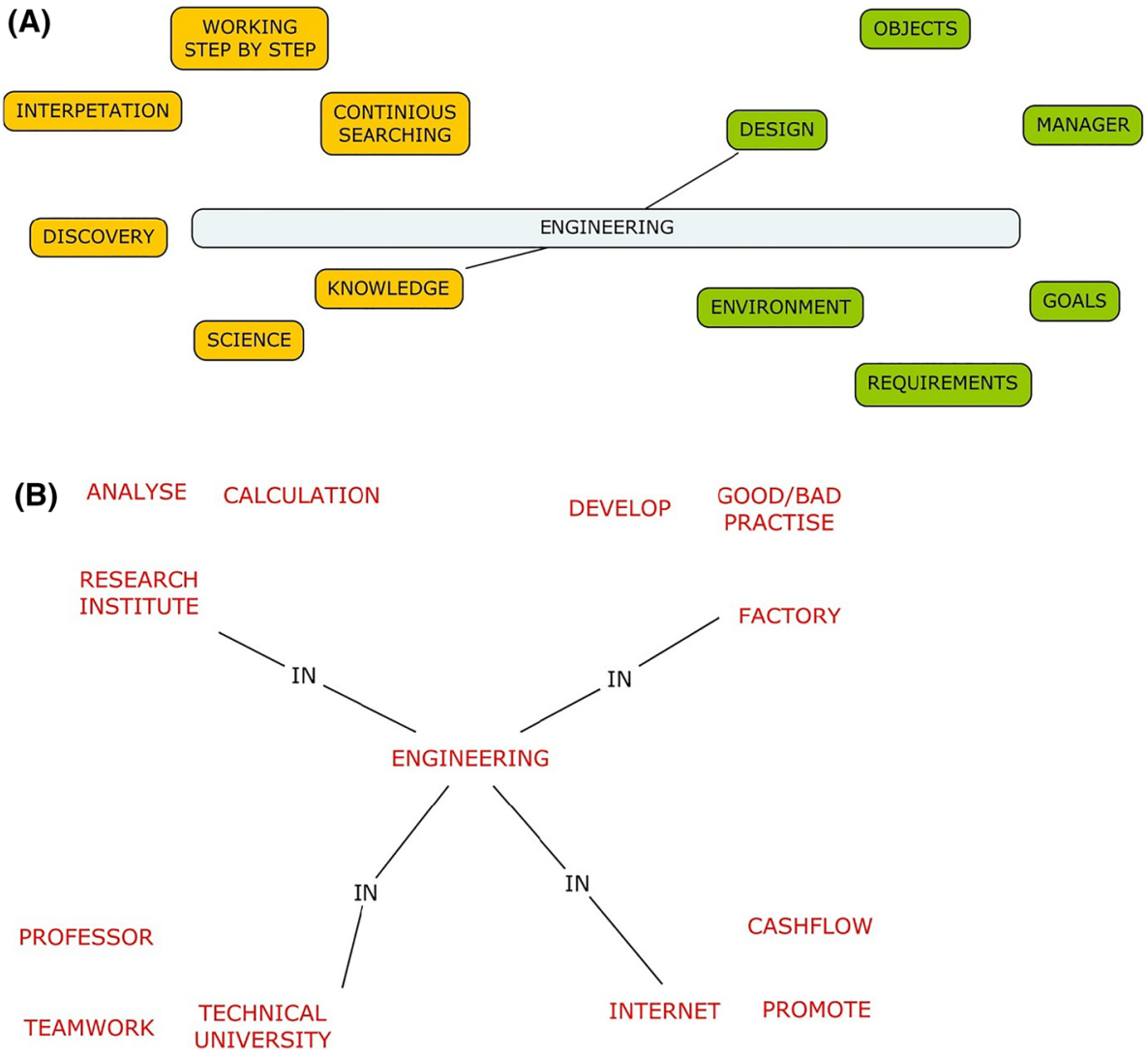

Fig. 1 Two examples of concept maps. a Grishma, India, age 16; b Junichi, Japan, age 15

concept of technology was asked for by using a questionnaire. We found many keywords in the maps that reflected a fairly good understanding of what engineering is about. By comparing all keywords found in the concept maps, we were able to derive four main categories of keywords. Of course this way of 'coding' is never entirely without reference to existing ideas about the concept that is studied (engineering in our case). We know from literature (e.g. introductory books about engineering, and for instance the definition of engineering in the Free Dictionary (www.thefreedictionary.com): "The application of scientific and mathematical principles to practical ends such as the design, manufacture, and operation of efficient and economical structures, machines, processes, and systems"). That there is a research dimension to engineering, as well as a design and development dimension and also a social and managerial dimension (Nersessian 2005). With such ideas in mind, we analyzed the concept maps.

Many of these keywords were found in several concept maps. Two examples of concept maps with randomized pupils' names, countries and ages (for anonymity) are shown in Fig. 1.

Structure has been given to the list of keywords, by categorizing into relevant dimensions. The concept maps give the impression that pupils are aware of several different 
dimensions in engineering. Some keywords clearly refer to the research dimension in engineering (examples: analysis, calculating, continuous searching, research). This dimension was never found in studies about pupils' concepts of technology before. It can indeed be used to characterize the particular nature of engineering compared to the wider concept of technology: engineering has an important research component. Pupils also seem to be aware of the development dimension in engineering. They are able to mention details about that aspect, such as working with requirements, optimizing, drawing, making, testing, et cetera. It is interesting to see that in some concept maps even the term 'modelling' was found, which certainly reflects a fairly sophisticated insights into the nature of engineering. It is also interesting to see that many of the concept maps contained the managerial aspects of engineering (examples: managing, teamwork). Finally, we observed that pupils also show an awareness of the economic and social dimension of engineering (reflected in words like government, money, good/bad). We realize that it is possible that the teachers selected good pupils to draw the concept maps and that our sample is not representative for all pupils. Representativeness for all students was not the aim of the concept maps, however. We wanted to see what kinds of dimensions are present in the pupils' minds and not in what percentage of the pupils' minds these dimensions are present. With a factor analysis on the quantative data acquired with the questionaire, we wanted to find out whether dimensions were also present in the larger sample of students.

The resulting categories and examples of keywords for each category are presented in Table 2.

\section{Results: quantitative part (Likert-questionnaire)}

We present the final outcome of our research following a division in:

- a factor analysis that reveals the dimensions in the pupils' attitude towards and concept of engineering,

- the scale scores that were derived from this analysis as well as the differences between subpopulations.

Table 2 Categories of concepts in the pupils' concept maps

\begin{tabular}{|c|c|c|c|c|}
\hline Research component & $\begin{array}{l}\text { Development } \\
\text { component }\end{array}$ & $\begin{array}{l}\text { Production } \\
\text { component }\end{array}$ & $\begin{array}{l}\text { Marketing } \\
\text { component }\end{array}$ & $\begin{array}{l}\text { Other } \\
\text { keywords }\end{array}$ \\
\hline Calculations & Carry on & Factories & Cash flow & Machinist \\
\hline $\begin{array}{l}\text { Thinking/working in fixed } \\
\text { steps }\end{array}$ & Computers & Buildings & Managers & Art \\
\hline Discovery & Creativity & Government & Money & Clothing \\
\hline Research & Design & Mass production & Promote & \\
\hline Science & Future & Transport & Tools & \\
\hline Scientists & $\begin{array}{c}\text { Knowledge of } \\
\text { materials }\end{array}$ & & & \\
\hline Well-ordered & Modelling & & & \\
\hline Working with the head & Modern times & & & \\
\hline Work that never ends & Nature & & & \\
\hline
\end{tabular}


In total 7591 usable questionnaire results were received from the students in the various countries in which the questionnaire was administered. Yet, the variations in scores indicate that for many items there scores do not show extreme variations and it does make sense to look at the overall outcomes. Also we believe that the factors we found match so well with PATT studies and with what we found in the concept maps that we present them with confidence in their validity. An important validity argument is that the items that were most strongly correlated to a factor, in all cases allowed for a clear and unambiguous interpretation of the factor.

For the attitude part of the questionnaire, we found the factors seen in Table 3. The dimensions used as part of the Likert questionnaire, were obtained from the factor analysis. Items scoring higher than 0,8 on the Cronbach's alpha have been included. The ' $\mathrm{N}$ of items' column refers to the number of items that were selected to construct a scale score, based on the factor analysis (items scoring lower on a factor were dropped until a significant drop of Cronbach's alpha appeared). The Cronbach's alpha in the second column represents the reliability of that scale. Evidently, all scales are reliable when we use 0.80 as a minimum requirement.

These factors (and the derived scales) are similar to what had been found in PATTstudies (as well as in studies on attitudes towards science; in fact, they seem to be very general for attitudes (de Vries 2005; Dakers and de Vries 2009). Surprisingly, there is no gender factor, although that was found in nearly all PATT studies and gender-related items had been included in the questionnaire. These items had dissolved in the 'interest' and 'difficulty' factors and were not distinguishable as a separate dimension. A possible explanation for this, to be explored in further research, is that pupils in upper secondary education are beyond gender-related choices such as their curriculum profile (natural sciences or social sciences) and also they have moved significantly in their development towards adolescence and thus have overcome gender-related personality issues (Radford 1998); In other words: pupils at this school and age level appear to not want to be bothered by gender considerations anymore when thinking about technology or engineering.

For the concept part of the questionnaire, the factors seen in Table 4 were identified.

Here we find that four factors lead to reliable scales based on factor analysis, where naming and scaling was possible. These factors (scales) clearly match with what we had found in the concept maps. Compared to what was found in PATT studies, the research dimension stands out as particular for engineering. This matches well with reality. Engineers do a lot of research and this distinguishes them from technicians and do-it-your-self hobbyists. An interesting question, to be researched further, is how pupils have learnt this. In most countries, engineering is not part of their curriculum. Perhaps the popularity of some television programs as broadcasted by Discovery Channel and the National Geographic Channel, in which research often features as part of engineers' work, has had an

Table 3 Attitude factors (scales)

\begin{tabular}{llccc}
\hline Factor & Cronbach's alpha & N of items & \% of variance & Cumulative \% \\
\hline Interest & 0.965 & 9 & 21.817 & 21.817 \\
Importance (social) & 0.862 & 11 & 20.456 & 42.273 \\
Difficulty & 0.940 & 6 & 16.825 & 59.098 \\
Assessment (good or bad) & 0.903 & 5 & 15.292 & 74.390 \\
\hline
\end{tabular}


Table 4 Concept factors (scales)

\begin{tabular}{lllll}
\hline Factor & Cronbach's alpha & N of items & \% of variance & Cumulative \% \\
\hline Research & 0.944 & 8 & 21.369 & 21.369 \\
Development & 0.942 & 9 & 19.062 & 40.431 \\
Production & 0.971 & 5 & 14.065 & 54.496 \\
Marketing & 0.917 & 5 & 11.711 & 66.207 \\
\hline
\end{tabular}

impact on what pupils think of engineering. In general, pupils in upper secondary education seem to be much more aware of the process character of engineering than lower secondary school pupils are aware of the process character of technology. For most PATT studies, it was found that lower secondary school pupils associate technology mostly with artefacts/products, not with processes of creation or invention.

The scores per scale are presented in Table 5.

Here are the scores from the survey (Likert scale of 1-4).

As for interest perception: 1 means very much interested and 4 means a low interest. Generally speaking here we observe that many students are interested in engineering.

For importance: 1 means extremely important and 4 means not important. Regarding importance, the pupils are almost neutral towards it.

For difficulty: 1 means a high level of difficulty and 4 indicates a low level of difficulty. With a score of 2149 , we can generally say that the students find the courses related to engineering very difficult.

For assessment: 1 means good 4 means bad social impacts. The results show that students think that engineers have brought the society much good.

Interest, importance, difficulty and assessment together form the attitude-scale.

Research, development, production and marketing are the four scales that make up the image scale about engineering.

For research: 1 represents that research is an important part of the research image, and 4 says it does not constitute a significant part of the image. According to these results, students see research as an important aspect of engineering.

For development: 1 indicates development is an important part of engineering, and 4 means that development is not an important part of engineering. Students according to these results see an important role for a development as part of engineering.

For production: 1 means production forms an important part of engineering, and 4 means that production does not play an important part in engineering. These results indicate that for the students, production generally plays an important role.

For marketing: 1 means marketing is an important part of the image and 4 indicates it does not constitute a significant part of the image. Students seem to see an important role for marketing as part of engineering as well.

As can be seen in Table 5, for each part there is a large standard deviation. This indicates that the influence of a country as a background variable largely determines the perceptions of the pupils.

It is interesting which of the background variable has the most significant effect on attitudes and concepts. To find that out, we did regression analysis on the data. We included the differences between country groups in this analysis. The relation between the background variables and the scale scores has been shown by conducting a regression 


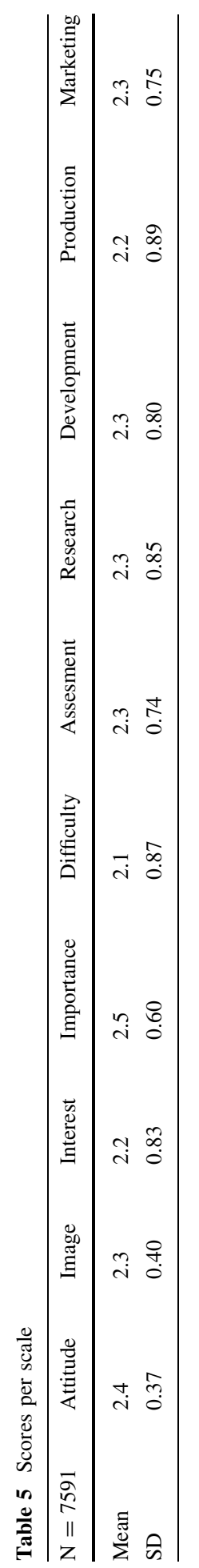




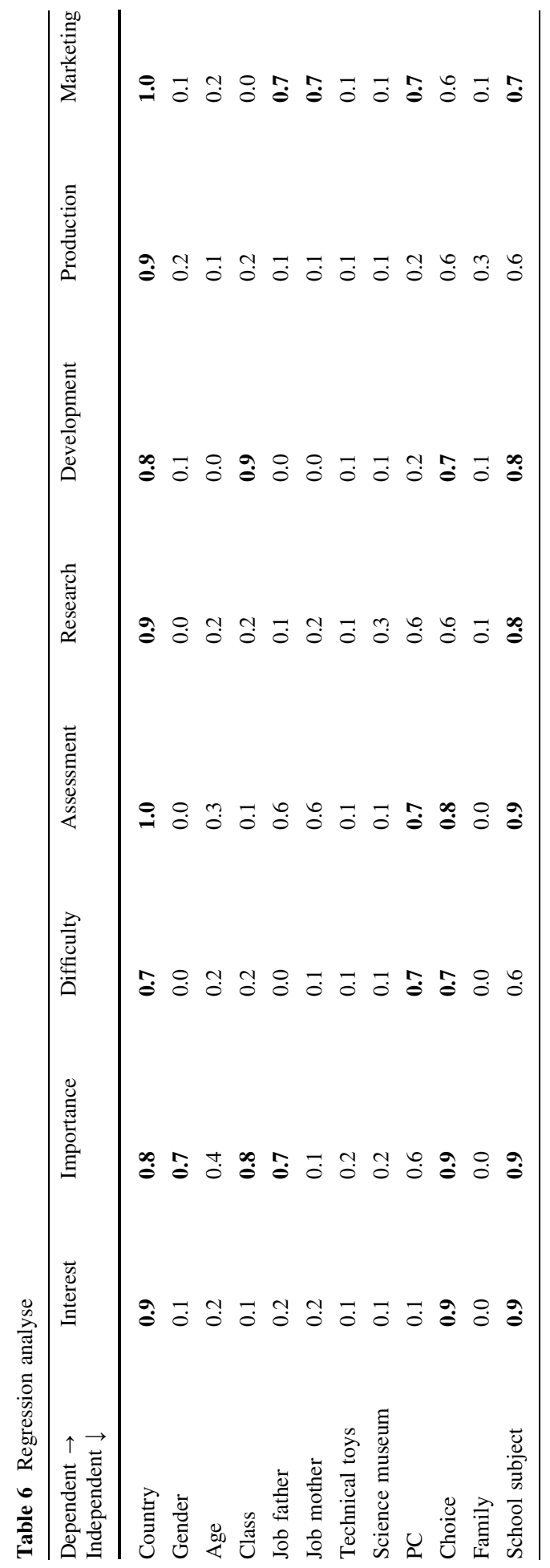


analysis. The results are presented in Table 6. Significant correlations are printed in a bold face.

From this regression analysis, it appears that the country of the respondents has a significant effect on the attitude of students towards engineering and also the image of students towards engineering. Other background variables do not exert a significant effect. In this article we will therefore examine the background variable 'country of the pupil' in some more detail. Concurrently, in addition to the country as a variable, the presence of school subject and student's choice have a significant impact on the image and attitude towards engineering. All other variables have a limited effect. In this article we have chosen only for country/region to be described in more detail. We choose not to use t-tests, as these can only be applied to some of the background variables (those with two subgroups only). In Table 7 the scale scores are presented per region. Significant differences are printed in bold.

Here we must mention that the differences seem small, but that according to the regression analysis they are nevertheless significant. We realise this happens more easily with these large numbers of respondents than with small numbers. Nevertheless, we think the differences are worth considering. Our considerations here are only tentative; more extensive study would be necessary to find out if the suggestions made are have real significance.

We start with the attitude-related items:

Interest: Pupils generally show an interest in engineering (scores on interest items of 2.2 on the 4-point scale with score 1 as very interesting. This is similar to what was found for technology in PATT studies (de Vries 2005); If we compare the clusters of countries we see that pupils in the Far East, Eastern Europe and South Asia show the most interest in engineering. We will present some speculations as to what might be the cause of these differences. We immediately add to this that it can be questioned if the differences in the role of engineering between regions that are described in literature are perceived indeed by pupils of this age. But as they probably have become regular readers of newspapers and watchers of news broadcasts, their awareness of how engineering impacts their own country may have developed sufficiently to be traceable in our survey.

During the Industrial Revolution, a period from 1750 to 1850 , there where changes in agriculture, manufacturing, mining, transportation, and 'technology' had a profound effect on the social, economic and cultural conditions of the times. It began in Western Europe, North America, Japan, and spread in the rest of the world (Maddison 2003). In an industrial society, there was a rapid growth of both the factories and the urban population. Economically, you can describe a factory as a machining process where raw materials enter and valuable products developed. Due to the enormous growth of factories in the seventies, there had be a reduction in the workforce in Western Countries (Davies 2004). The trend towards outsourcing was fed by strategic considerations. Many companies decide to outsource because it cut costs such as labor costs, regulatory costs, and training costs. Asian countries tend to have workers who will complete the same amount of work as in the United States, but for less than half the salary that an American employee will make (Hira and Hira 2008). Now the production divisions of large companies have established themselves in developing countries, would that have brought a shift in the minds of people towards engineering. The socio-economic, political and historical characteristics of countries would be able to explain to the opinions of residents, including students.

Importance: Pupils are aware of the importance of technology (scores of around 2.3 on the 4-point scale with 1 as very important). This, too, is similar to what PATT studies 


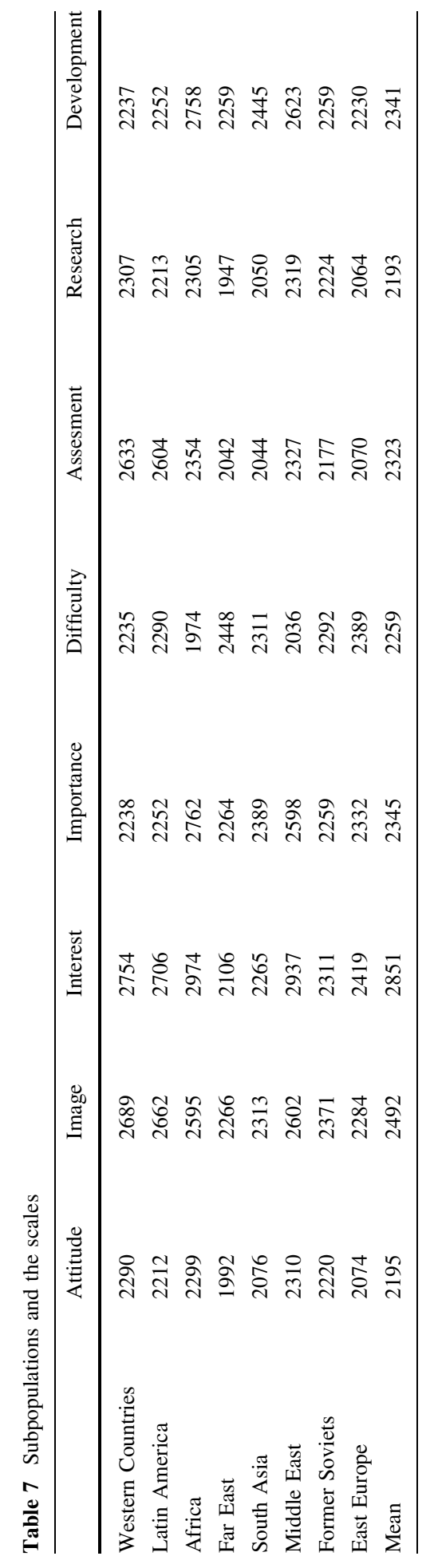


showed for technology; If we compare the subpopulations we see again that students in the Far East, Eastern Europe and South Asia find engineering the most important. Students from the Former Sovjets consider an average importance of engineering. Students from Western Countries, Africa and Middle East and Latin America consider a lower importance of engineering when we compare them with the rest of the students of the world. Again we see that developing countries who are closing the gap with Western knowledge economies, transfer their overtaking urge to the students in their own country (The World Bank 2009) It is remarkable that students from the developed countries of the west have an opposite attitude. They seem to think engineering is less important than the pupils of other regions.

Difficulty: Pupils think that engineering is not too difficult for them (score around 2.3 on the 4-point scale with 1 for not accessible). This too is similar to what was found in PATT studies. The degree of difficulty also depends on how many hours the students are taught in the STEM subjects. These are students who already have chosen subjects in the sciencedirection. However, a student in the Netherlands is taught with an average of $2 \mathrm{~h}$ per week in physics, while students in Japan receive 5 h (CBS 2011). Because of an international BAMA structure introduced in 1999, the expected learning outcomes of secondary education in these subjects is more or less equalized (Bologna Process 1999). Also, the admission tests to colleges and universities are different. While the top ten percent of students in Turkey be able to study an engineering study because of the quota, students work harder on average to be admitted. The need to work harder reduces the difficulty.

Assessment: Pupils generally believe engineering brings about more good things than bad things (scores of around 2.30 on the 4-point scale with 1 as more good than bad things). This, too, matches with what PATT studies showed for technology. But students in the Middle East and Africa indicate that the wars and coups happening in the area are also fed with products made by engineers. One student's answer was very characteristic for those groups: "Engineers have researched and invented products. Those inventions are discovered fields of raw materials such as, diamond, gold and oil. With this people became rich. In order to stay rich, they have wars or take coups. This also happened with the discoveries of engineers. The weapons are also made by them. With weapons are there people slain in Africa and Middle east. Engineers have unknowingly broken a lot".

The gender item scores tend to veer more towards the neutral point of the scale than the other interest scores. Pupils indicate that they do not have strong opinions on this. This confirms the fact that gender did not come out as a separate factor.

For the concept-related items, we observe that all four dimensions found in the factor analysis have item scores between 2.1 and 2.4 and items that have higher scores mostly refer to 'softer' issues (for instance, artistic aspects and clothing).

The following are concept-related items:

Research: Because the students in Africa and the Middle East do not always have the devices that are present in Western Countries, they think that is because of discoveries made in the West. This corresponds to historical economic characteristics of the West, obtained in the industrialization and economy (OECD 1999). In the early twenty-first century businesses increasingly outsourced to suppliers outside their own nation. Western companies were able to focus their money and resources more towards improving the core aspects of its business when outsourced, mostly research and development. For example Philips had in the years after World War II $90 \%$ of all its divisions in the Netherlands. Now only $10 \%$ of Philips Research remained in the Netherlands. The rest are outsourced 
to India and Poland. (OECD 2006) This will help to give an explanation about the image that students in the Western Countries.

Development: Countries where the production departments have gone to were the Far East, Southern Asia and Eastern Europe. This could be an explaining factor of the students' image of development in those countries.

Production: Countries like China and India have gained by outsourcing many manufacturing divisions. The area is full of factories, while in London for example, there is no more factory to see. The image of engineering by students depends either on their environment. Their environment in Far East, South Asia and East Europe is filled with factories and production (CIA Factbook 2010).

Marketing: The students see that more and more products designed by engineers had also a part in marketing. For example they use devices as an Iphone, designed by Apple in California, assembled in China, as a very good selling product.

\section{Conclusion and discussion}

Our study suggests that upper secondary school children have a fairly good idea of what engineering is and they generally have a positive attitude towards it. The former differs from what was found in previous PATT studies (Dakers and de Vries 2009) for lower secondary and primary pupils, and for technology instead of engineering. Our results also suggest a more rich concept of engineering than was found among younger children (Karatas et al. 2010; Knight and Cunningham 2004). That is a favorable outcome for developing engineering-related activities in upper secondary education, as it seems that there is a certain foundation already onto which can be built further. The results of this study are not always consistent with prior work in the field. Prior studies suggested elementary-, and middle school students as most likely to cite making or assembling vehicles and building structures as examples of the process of engineering (Fralick et al. 2009; Knight and Cunningham 2004; Lyons and Thompson 2006; Karatas et al. 2010). The secondary high school students between the ages of 15 and 18, which were included in our study, were more likely than participants in prior work to invoke the image of engineers researching or developing a product as part of the engineering process. They also have the idea that engineers are involved in the production of materials and the marketing part of it. The images of the nature of engineering that emerged in this study suggest that engineering is an active process. Almost all of the students' concept maps included some form of research, whether it was at a university or a science centre, developing a product, inventing, or to produce a product in a factory. Selling the products was also mentioned as a dimension of engineering, which suggests that more elements of engineering were seen in this study than in prior work. Generally there was no large demarcation in this study between students who believed that engineers are researching or developing products and those who focused on the process by which engineers supposedly take part of the production part of it and build the product and selling the products. It was apparent in both the drawings and the interview data that engineering was seen as something that was done by skilled craftsmen who are involved in the research, development, production and marketing processes. An indicator that the students' views of engineers and engineering were surprisingly well developed could be seen in the students' existence of self-confidence in their responses. This was shown by the tendency for the students to all respond at some point in the interview with "I absolute agree", or "I totally disagree with", and prosecute 
the discussion of that particular topic when the teachers and the researcher tried to confirm their responses.

When the students were asked whether engineering is "male profession," their response was negative. $74 \%$ of the male and $81 \%$ of the female students' clearly indicated that women are just as good as they were in engineering, which is not consistent with prior work that suggests that middle-school boys have stronger aspirations toward technologically oriented jobs than girls (Bame and Dugger 1989; de Klerk Wolters 1989). The inconsistency between the near absence of female engineers in the society and universities and the results of this study, could maybe summarized with "Yes, we can, because we have better marks in science". This hypothesis needs to be tested in future studies.

The analysis of the data collected in this study showed similarities between the content of the students' concept maps and their answers to the questionnaire. These clearly match, even though the questionnaires were collected for a higher number of students and countries. Compared to what was found in PATT studies, the research dimension stands out as a specific part of engineering. This corresponds well with reality. Engineers do a lot of research and this distinguishes them from technicians and do-it-your-self hobbyists. An interesting question, to be researched further, is how pupils have learnt this. In most countries, engineering is not part of their curriculum. Perhaps the popularity of some television programs as broadcasted by Discovery Channel and the National Geographic Channel, in which research often features as part of engineers' work, has had an impact on what pupils think of engineering.

In summary, for education the conclusion could be drawn that each country group needs a separate structure related to pre-university Engineering Education. The students already have a very clear image which engineering is, but have a more regional emphasis on various parts of engineering. Pupils generally have shown that engineering includes four parts: research, development, production and marketing. For example, in the Netherlands as a Western country there should be more emphasis on attitude component importance, as well as image component development. And in China as a Far East country there should be more attention for on the image component research. Lesson sets with more emphasis on research, would improve the image of students from China on that aspect, without losing sight of other components. It could be built on the very clear image of what pupils appear to have on development, marketing and production in particular.

Open Access This article is distributed under the terms of the Creative Commons Attribution License which permits any use, distribution, and reproduction in any medium, provided the original author(s) and the source are credited.

\section{References}

Bame, E., \& Dugger, W., Jr. (1989). Pupils' attitude toward technology-PATT-USA Report Findings. Resource document. http://www.iteaconnect.org/Conference/PATT/PATTSI/PATT\%20USA.pdf. Accessed 1 January 2013.

Bame, E. A., Dugger, W. E., \& de Vries, M. J. (1993). Pupils' attitudes towards technology: PATT-USA. Journal of Technology Studies, 19(1), 40-48.

Bologna Process (1999). Joint declaration of the European Ministers of Education Resource document. The European Higher Education Area. http://www.ond.vlaanderen.be/hogeronderwijs/bologna/documents/ MDC/BOLOGNA_DECLARATION1.pdfAccessed. Accessed 18 May 2013.

CBS (2011) Voortgezet onderwijs; deelname leerlingen naar onderwijssoort. Resource document. Dutch national institute of statistics. http://statline.cbs.nl/StatWeb/publication/?VW=T\&DM=SLNL\&PA= 80040NED\&D1=0,3,6-8,14-15,19-21,55,57-59,61-64,69-70,72-74,76-79,84\&D2=0\&D3=0\&D4=0-1,3-4, 
1\&D5=1\&D6=0\&D7=6-8\&HD=120524-1553\&HDR=G4,G5,G1,G2,G3,G6\&STB=T. Accessed 11 May 2011.

CIA (2010) The World Factbook 2010. Resource document. Central Intelligence Agency https://www.cia. gov/library/publications/the-world-factbook/geos/in.html. Accessed 19 June 2010.

Committee on Standards for K-12 Engineering Education. (2010). Standards for K-12 engineering education?. Washington, DC: The National Academies Press.

Dakers, J. D., \& de Vries, M. J. (2009). Perceptions of technology and technology education. In A. Jones \& M. J. de Vries (Eds.), International handbook of research and development in technology education (pp. 201-210). Rotterdam/Taipei: Sense Publishers.

Davies, Paul. (2004). What's this India Business?: Offshoring, Outsourcing, and the Global Services Revolution. London: Nicholas Brealey International.

De Klerk Wolters, F. (1989). The attitudes of pupils towards technology. Dissertation Eindhoven University of Technology. Resource document. http://alexandria.tue.n1/extra3/proefschrift/PRF6B/8909678.pdf. Accessed 12 January 2013.

de Vries, M. J. (2005). Teaching about technology. An introduction to the philosophy of technology for nonphilosophers. Dordrecht: Springer.

Fralick, B., Kearn, J., Thompson, S., \& Lyons, J. (2009). How middle schoolers draw engineers and scientists. Technology Studies. Journal of Science Education and Technology, 18(1), 60-73.

Hacker, M., Rossouw, A., \& De Vries, M. (2009). Concepts and contexts in engineering and technology education. Resource document. CCETE Project. http://www.ecent.nl/servlet/supportBinaryFiles?referenceId= 22\&supportId=2560. Accessed 10 January 2011.

Hira, R., \& Hira, A. (2008). Outsourcing America: What's behind our national crisis and how we can reclaim American jobs?. New York: AMACOM.

Karatas, F. O., Micklos, A., \& Bodner, G. (2010). Sixth-grade students View of the nature of engineering and images of engineers. Journal of Science Education and Technology,. doi:10.1007/s10956-0109239-2.

KlerkWolters, F., Raat, J. H., \& Vries, M. J. (1990). Assessing students' attitudes towards technology. Innovations in science and technology education, 3, 111-121.

Knight, M., \& Cunningham, C. (2004). Draw an engineer test (DAET): Development of a tool to investigate students' ideas about engineers and engineering. In Proceedings of the 2004 American Society for Engineering Education Annual Conference \& Exposition, Session 2530.

Lyons, J., \& Thompson, S. (2006). Investigating the long-term impact of an engineering-based GK12 program on students' perceptions of engineering. In Proceedings of the 2006 ASEE Annual Conference and Exposition, Chicago, Illinois pp. 18-21.

Maddison, A. (2003). The world economy historical statistics. Paris: Development Centre OECD.

Nersessian, N. J. (2005). Interpreting scientific and engineering practices: Integrating the cognitive, social and cultural dimensions. In M. E. Gorman, R. D. Tweney, D. C. Gooding, \& A. P. Kincannon (Eds.), Scientific and technological thinking (pp. 17-56). Mahwah, NJ: Erlbaum.

OECD (1999). Employment protection and labour market performance. Resource document. OECD http:// www.oecd.org/els/emp/2079974.pdf. Accessed 12 May 2011.

OECD (2006). Productivity impacts of offshoring and outsourcing: A review. Resource document. OECD Directorate for Science, Technology and Industry (STI) http://www.oecd.org/science/sci-tech/ 36231337.pdf. Accessed 12 May 2013.

Radford, D. L. (1998) Transferring theory into practice: A model for professional development for science education reform. Journal of Research in Science Teaching. doi: 10.1002/(SICI)1098-2736(199801)35: $1<73:$ :AID-TEA5 $>3.0 . \mathrm{CO} ; 2-\mathrm{K}$.

The World Bank (2009). The World Bank Annual Report 2009. Resource document. The World Bank http:// siteresources.worldbank.org/EXTAR2009/Resources/62239771252950831873/AR09_Complete.pdf. Accessed 12 May 2011. 